Document downloaded from:

http://hdl.handle.net/10251/83223

This paper must be cited as:

Hassan, AHA.; Martinez Ballester, S.; Gonzálvez Maciá, J. (2016). Two-dimensional numerical modeling for the air-side of minichannel evaporators accounting for partial dehumidification scenarios and tube-to-tube heat conduction. International Journal of Refrigeration. 67:90-101. doi:10.1016/j.jirefrig.2016.04.003.

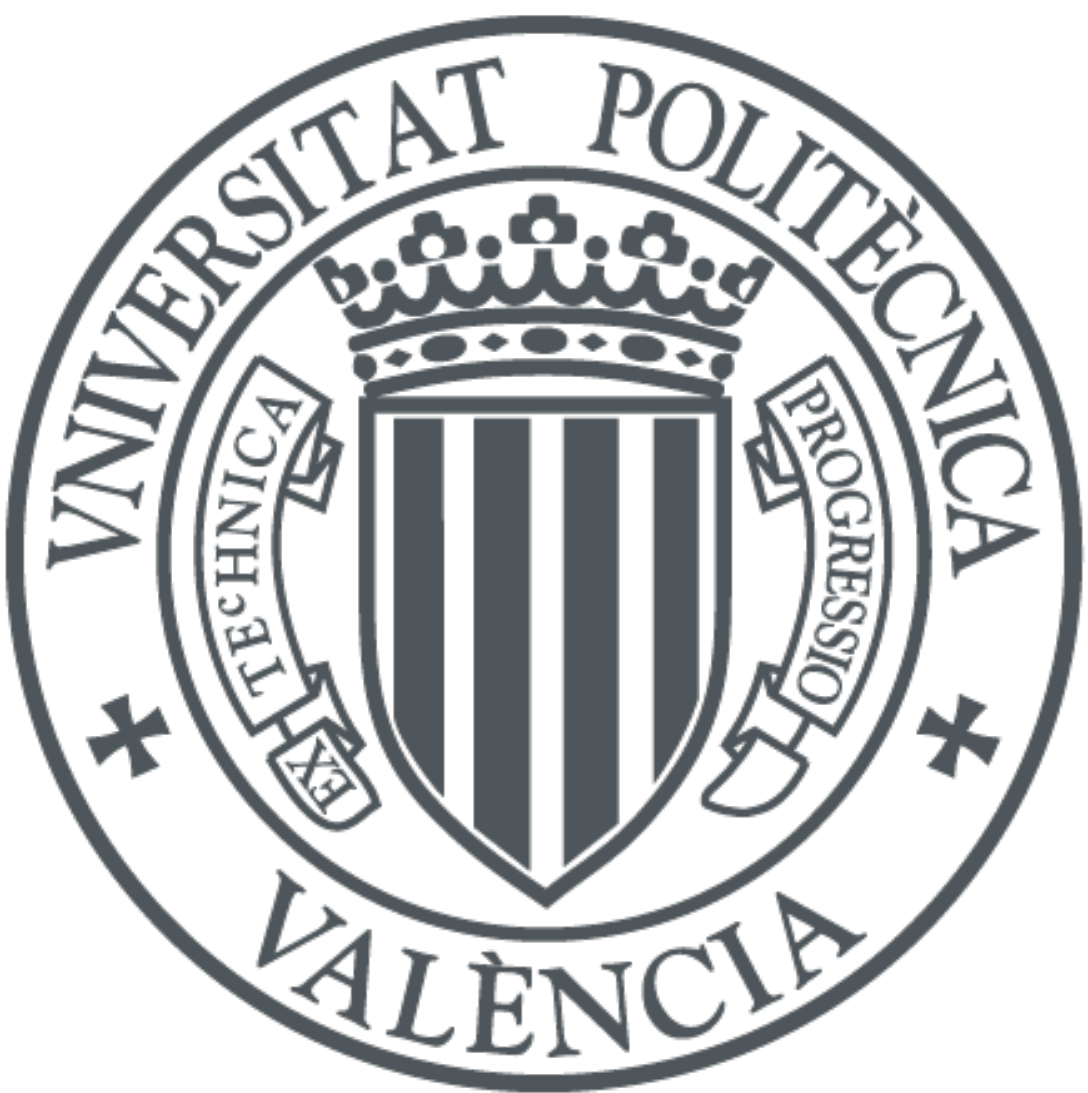

The final publication is available at

http://doi.org/10.1016/j.ijrefrig.2016.04.003

Copyright Elsevier

Additional Information 


\section{Accepted Manuscript}

Title: Two-dimensional numerical modeling for the air-side of minichannel evaporators accounting for partial dehumidification scenarios and tube-to-tube heat conduction.

Author: Abdelrahman Hussein Hassan, Santiago Martínez-Ballester, José Gonzálvez-Maciá

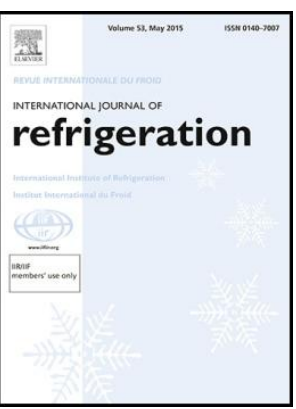

PII:

S0140-7007(16)30044-5

DOI: $\quad$ http://dx.doi.org/doi: 10.1016/j.ijrefrig.2016.04.003

Reference: JIJR 3302

To appear in: International Journal of Refrigeration

Received date: $\quad 8-10-2015$

Revised date: $\quad 30-3-2016$

Accepted date: 3-4-2016

Please cite this article as: Abdelrahman Hussein Hassan, Santiago Martínez-Ballester, José Gonzálvez-Maciá, Two-dimensional numerical modeling for the air-side of minichannel evaporators accounting for partial dehumidification scenarios and tube-to-tube heat conduction., International Journal of Refrigeration (2016), http://dx.doi.org/doi:

10.1016/j.ijrefrig.2016.04.003.

This is a PDF file of an unedited manuscript that has been accepted for publication. As a service to our customers we are providing this early version of the manuscript. The manuscript will undergo copyediting, typesetting, and review of the resulting proof before it is published in its final form. Please note that during the production process errors may be discovered which could affect the content, and all legal disclaimers that apply to the journal pertain. 


\title{
TWO-DIMENSIONAL NUMERICAL MODELING FOR THE AIR-SIDE OF MINICHANNEL EVAPORATORS ACCOUNTING FOR PARTIAL DEHUMIDIFICATION SCENARIOS AND TUBE-TO-TUBE HEAT CONDUCTION.
}

\author{
Abdelrahman Hussein Hassan, Santiago Martínez-Ballester*, José Gonzálvez-Maciá \\ Institute for Energy Engineering, Universitat Politècnica de València, Camino de Vera s/n, Valencia 46022, Spain. \\ *Corresponding Author. Tel.: +34 963879120, Fax: +34 96389126, E-mail: sanmarba@ gmail.com (S. Martínez- \\ Ballester).
}

\section{Highlights}

- A 2D model for air-side performance of minichannel evaporators is proposed.

- The classical $\varepsilon-\mathrm{NTU}$ approach is compared with the current model.

- The $\varepsilon-\mathrm{NTU}$ approach fails to predict the actual fin dehumidifying condition.

- Assuming adiabatic-fin-tip results to large deviations in fin temperature profile.

- The deviations in total heat transfer between the two models are up to $52 \%$.

\begin{abstract}
This paper presents a comparative study between the air-side heat transfer results of a two-dimensional numerical model for minichannel evaporators (Fin2D-W), and the results of the classical $\varepsilon$-NTU approach. This study is carried out for different dehumidifying conditions, and for scenarios with different degree of temperature difference between tubes due to the refrigerant superheat. The Fin2D-W model solves the two-dimensional heat conduction in the fin wall considering also a 2D discretization for the air flow in contact with it. Thus, the presented model is able to capture the partial dehumidification scenarios and the effect of the heat conduction between tubes. The results analyze the differences, due to these phenomena, between the proposed model and the classical approach. Significant deviations between the two models are reported, especially in the cases of partially wet fin and high values of superheat, resulting in being up to $\approx 52 \%$ in total heat transfer.
\end{abstract}

Keywords: minichannel evaporator, modeling, air-side analysis, heat transfer, mass transfer. 


\section{NOMENCLATURE}

\begin{tabular}{|c|c|c|c|}
\hline$A$ & surface area $\left[\mathrm{m}^{2}\right]$ & \multicolumn{2}{|c|}{ Greek symbols } \\
\hline$a$ & parameter defined in Eq. $5\left[\mathrm{~kg}_{\mathrm{w}} \mathrm{kg}_{\mathrm{da}}{ }^{-1}\right]$ & $\alpha$ & 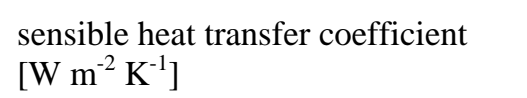 \\
\hline$b$ & slope of saturated humidity ratio line $\left[\mathrm{K}^{-1}\right]$ & $\alpha_{D}$ & mass transfer coefficient $\left[\mathrm{kg} \mathrm{m}^{-2} \mathrm{~s}^{-1}\right]$ \\
\hline$C_{p}$ & specific heat $\left[\mathrm{J} \mathrm{kg}^{-1} \mathrm{~K}^{-1}\right]$ & $\alpha_{\text {wet }}$ & $\begin{array}{l}\text { total heat transfer coefficient for wet } \\
\text { case }\left[\mathrm{W} \mathrm{m}^{-2} \mathrm{~K}^{-1}\right]\end{array}$ \\
\hline G & mass flux $\left[\mathrm{kg} \mathrm{m}^{-2} \mathrm{~s}^{-1}\right]$ & $\beta$ & parameter defined in Eq. $6[\mathrm{~K}]$ \\
\hline $\mathrm{H}_{\mathrm{f}}$ & fin height $[\mathrm{m}]$ & $\varepsilon$ & thermal effectiveness [-] \\
\hline$h_{f g}$ & latent heat of water condensation $\left[\mathrm{J} \mathrm{kg}^{-1}\right]$ & $\eta$ & thermal efficiency $[-]$ \\
\hline$k$ & conductivity $\left[\mathrm{W} \mathrm{m}^{-1} \mathrm{~K}^{-1}\right]$ & $\lambda$ & thermal conductance $\left[\mathrm{W} \mathrm{K}^{-1}\right]$ \\
\hline$l$ & distance between two wall cells [m] & \multicolumn{2}{|l|}{ Subscripts } \\
\hline Le & Lewis number $[-]$ & $a$ & air \\
\hline$\dot{m}$ & mass flow rate $\left[\mathrm{kg} \mathrm{s}^{-1}\right]$ & $c$ & centroid of wall cell \\
\hline NTU & number of transfer units $[-]$ & $d p$ & dew point \\
\hline$P$ & perimeter $[\mathrm{m}]$ & \multirow{2}{*}{\multicolumn{2}{|c|}{$f$}} \\
\hline$\dot{Q}$ & heat transfer [W] & & \\
\hline$\dot{q}$ & heat flux $\left[\mathrm{W} \mathrm{m}^{-2}\right]$ & & fluid cell index \\
\hline $\mathrm{RH}$ & relative humidity [\%] & $j$ & wall cell index \\
\hline$s$ & length in the direction of a fluid $[\mathrm{m}]$ & $k$ & direction index \\
\hline $\mathrm{SH}$ & superheat $=T_{u t}-T_{l t}[K]$ & lt & lower tube \\
\hline$T$ & temperature $\left[{ }^{\circ} \mathrm{C}\right]$ & $\mathrm{ma}$ & moist air \\
\hline$T^{*}$ & modified moist air temperature $\left[{ }^{\circ} \mathrm{C}\right]$ & \multirow{2}{*}{$\begin{array}{l}N, S, W, E \\
s\end{array}$} & directions of neighbor wall cell \\
\hline$t$ & thickness $[\mathrm{m}]$ & & surface of wall cell \\
\hline$U_{\text {wet }}$ & $\begin{array}{l}\text { overall heat transfer coefficient for wet case } \\
{\left[\mathrm{W} \mathrm{m} \mathrm{m}^{-2} \mathrm{~K}^{-1}\right]}\end{array}$ & sat & saturated \\
\hline$W$ & humidity ratio $\left[\mathrm{kg}_{\mathrm{w}} \mathrm{kg}_{\mathrm{da}}^{-1}\right]$ & tot & total \\
\hline$x, y, z$ & spatial coordinates $[\mathrm{m}]$ & ut & upper tube \\
\hline & & \multicolumn{2}{|c|}{ Superscripts } \\
\hline & & in & inlet \\
\hline
\end{tabular}




\section{INTRODUCTION}

Currently, several models or simulation tools for heat exchangers are available in the literature: for conventionalchannel (Liang et al., 2001; Corberán et al., 2002; Domanski, 2003; Jiang et al., 2006; Singh et al., 2008; IMSTART, 2010); and for minichannel (Wu and Webb, 2002; Asinari et al., 2004; Martínez-Ballester et al., 2011; Zhao et al., 2012; Gossard et al., 2013; Ren et al., 2013; Huang et al., 2015; Yin et al., 2015).

To allow for good and accurate modeling of the heat exchangers, a discretization process is required. The tubes of the heat exchanger are divided into a number of segments, usually along the refrigerant flow direction, with its corresponding fins. Each segment represents an individual heat exchanger which could be evaluated by classical global methods, i.e., the logarithmic mean temperature difference (LMTD), logarithmic mean enthalpy difference (LMHD), $\varepsilon-\mathrm{NTU}$, and so on. However, on the other hand, those segments could be additionally discretized into a number of cells using finite volume method (FVM) or finite element method (FEM). For each cell heat and mass balances are implemented. The main difference between the two methodologies is that the classical global methods have several implicit assumptions resulting in less freedom to describe the actual processes. These include, for example, no heat conduction between tubes along the fin (adiabatic-fin-tip assumption), negligible effect of longitudinal heat conduction (LHC), and uniform air temperature along the fin height.

The impact of these assumptions on the air-side performance of minichannel gas coolers and condensers were extensively discussed by Asinari et al. (2004), Martínez-Ballester et al. (2011), and Yin et al. (2015). However, more assumptions are employed when modeling minichannel evaporators under dehumidification, such as:

- Uniform humidity ratio along the fin height. This assumption is a consequence of using the fin theory which also assumes a uniform air temperature profile within the same direction. Martínez-Ballester et al. (2011) concluded in their study that a notable air temperature gradient exists near tubes, which also extends far from the boundary layer region. This fact could have an important impact on local effects controlling the heat and mass transfer, e.g. dehumidification.

- No consideration of partial fin dehumidification. When the heat exchanger is used as an evaporator, its wall surface temperature is usually below the average dew point of the surrounding moist air. This results in simultaneous heat and mass transfer. However, some locations on the fin surface could be wet, and some others could be dry, due to the fin temperature gradient. The fin temperature profile and, therefore, the local dehumidifying 
condition depend on the local dew point of surrounding air, fin roots temperatures, and fin efficiency. To identify the surface area below or above the dew point along both the tube and the associated fin is considered to be a challenge in modeling evaporators for simulation tools. Thus, most of evaporator models in the literature usually assume that the whole evaporator segment is either completely dry or wet based on: the tube surface temperature (Zhao et al., 2012); or the average wall surface temperature for the tube and fin, to capture the effect of fin temperature profile (Jiang et al., 2006).

As noted from the previous literature review, these classical modeling assumptions have not been studied so extensively for evaporators, especially minichannel evaporators under different dehumidifying conditions. This motivated Hassan et al. (2015) to develop a fundamental 2D numerical model, referred to as Fin2D-W. This model has been considered to be an extension of the Fin2D model which was proposed by Martínez-Ballester et al. (2011). However, their model was basically developed for modeling the condensers and gas coolers; since it did not take into account the dehumidification process. The Fin2D-W model divides the whole evaporator to segments, which in turn are subdivided into different cells. The energy and mass balances are applied to each cell without using any classical modeling assumption. This numerical model takes into account the $2 \mathrm{D}$ heat conduction in any wall element (fin or tube), does not apply the fin theory, captures a detailed representation of air properties in both longitudinal and transverse directions, and finally accounts for partial dehumidification scenarios for the fin and tube. Hassan et al. (2015) compared the numerical results of the Fin2D-W model with the classical $\varepsilon-N T U$ method which was based on all the above mentioned assumptions. In their work the same temperature for upper and lower tubes was assumed, accordingly the assumption of adiabatic-fin-tip at half the height was exactly correct in this case. The main conclusions of their study were as follows:

- For the totally dry fin, the $\varepsilon$-NTU approach overestimated the sensible heat transfer by approximately $4 \%$. The main source of this deviation could be the assumption of uniform air temperature between tubes.

- For the partially wet fin, the $\varepsilon-\mathrm{NTU}$ approach always fails to predict the actual fin status because it does not account for partially wet scenarios. This resulted in significant deviations, especially in latent heat transfer, between the two approaches.

- For the totally wet fin, the $\varepsilon$-NTU approach generally overpredicts the sensible, latent, and total heat transfer rates for all inlet air cases studied. The average deviation in total heat transfer rate was $4.11 \%$. The main source of 
divergence between the two approaches is the assumption of constant air temperature and humidity ratio between tubes.

- The $\varepsilon-\mathrm{NTU}$ model was five times faster than the Fin2D-W model, for all the cases studied.

Also, the results showed that the range of partially wet fin was very small, due to the high fin efficiency. However in evaporators, there is usually a region of refrigerant superheat. This, subsequently, results in a temperature difference between the neighboring tubes which, in turn, results in a significant temperature gradient in the fin, regardless the fin efficiency. Under this situation, the assumption of adiabatic-fin-tip at half the height is not valid anymore, and the partial dehumidification scenarios have more impact on the heat and mass transfer rates. Hence in the current paper, the Fin2D-W model is employed to evaluate mainly these phenomena in minichannel evaporators operating with useful superheat.

\section{MODEL DESCRIPTION}

As discussed before, the proposed model is considered to be a fundamental numerical approach and a preliminary step to evaluate the impact of different classical modeling assumptions on the air-side performance of minichannel evaporators under dehumidifying conditions. This allows the authors to identify the phenomena and assumptions which have the greatest effect on the process of heat and mass transfer, subsequently, developing a more general evaporator model which will account for the most important phenomena in reasonable computation time.

\subsection{Evaporator Discretization}

Fig. 1a presents the main scheme used to discretize two tubes in minichannel evaporator. The tubes is discretized along the x-direction (refrigerant flow) in a number of segments "a". Each segment (Fig. 1b) consists of two streams of refrigerant (top and bottom flows) that are split into "b" channels in the z-direction (air flow); two flat tubes (top and bottom) that are discretized into "c" cells in the z-direction; and both air flow and fins, which are discretized in two dimensions: "d" cells in the y-direction and "e" cells in the z-direction. This is summarized in the text as a grid $\{a, b, c, d, e\}$. For illustration of the nomenclature, the numerical example shown in Fig. 1 corresponds to the grid $\{2,5,3,6,5\}$. However, the actual discretization grid used in the current study is defined later in Section 2. 


\subsection{Governing Equations}

Every fluid cell (refrigerant or air) has two nodes, which correspond to the inlet and the outlet in the fluid flow direction. The wall cells (tube or fin) have only one node located at the centroid of the cell, as shown in Fig. 2. All cell's local variables are referred to the value in these nodes; e.g. $T_{i}^{\text {in }}$ and $T_{i}^{\text {out }}$ are the temperature at the inlet and outlet, respectively, of a fluid cell $i . T_{c, j}$ is the temperatures of a wall cell $j$ defined at the centroid. The following assumptions are made to simplify the analysis:

a) the thermal conductivity of the fin and tube walls and latent heat of condensation of the water vapor are constant;

b) the moist air flow is steady with uniform inlet velocity distribution;

c) the condensate forms a smooth continuous film on the wall surface and flows under the effect of gravity only (Kuehn et al., 1998, ch. 11, p. 309; Coney et al., 1989b);

d) the thermal resistance associated with the presence of thin water film due to condensation is small and may be neglected (Coney et al., 1989a; Liang et al., 2000; Sharqawy and Zubair, 2008); and

e) the effect of air pressure drop due to air flow is neglected.

The analysis of refrigerant-side for the current model was already done by Martínez-Ballester et al. (2011), so the current paper only focuses on the air-side analysis of minichannel evaporators. In this situation, the governing equations can be expressed as follows.

\subsubsection{Moist air analysis}

In the Fin2D-W model, the air is dehumidified and cooled with decreasing the humidity ratio and dry-bulb temperature, respectively. The mass balance within any air cell $i$ in contact with $n_{i}$ wall cells is

$\dot{m}_{i} \cdot d W_{i}=\sum_{j=1}^{n_{i}}-\alpha_{D, i j}\left(W_{i}-W_{\mathrm{sat}, s, j}\right) P_{i j} \cdot d s_{i}$, if $\left(T_{s, j}<T_{d p, i}\right)$

$\dot{m}_{i} \cdot d W_{i}=0$, if $\left(T_{s, j} \geq T_{d p_{i}}\right)$

where 
$\alpha_{D, i j}=\frac{\alpha_{a, i j}}{L e_{i}{ }^{2 / 3} \cdot C_{p, \mathrm{ma}, i}} \quad$ is the mass transfer coefficient based on Chilton-Colburn analogy (Threlkeld, 1970).

While, the heat balance gives

$\dot{m}_{i} \cdot C_{p, \mathrm{ma}, i} \cdot d T_{i}=\sum_{j=1}^{n_{i}}-\alpha_{a, i j}\left(T_{i}-T_{s, j}\right) P_{i j} \cdot d s_{i}$

\subsubsection{Wall analysis}

The 2D energy balance within any wall cell $j$ in contact with $n_{j}$ fluid cells is represented by

$\nabla\left(k_{j, k} \cdot t_{j} \cdot \nabla T_{c, j}\right)+\sum_{i=1}^{n_{j}} \dot{q}_{\mathrm{tot}, i j}=0$

$k_{j, k}$ is the thermal conductivity of the wall cell $j$ in the $k$-direction. Thus it is possible to study the influence of $2 \mathrm{D}$ heat conduction at both fin and tube walls. The second term in Eq. 3 represents the summation of total heat transfer from/to surrounding fluids. The total heat transfer between any wall cell $j$ and corresponding moist air cell $i$ is defined in Eq. 4.

$$
\dot{q}_{\mathrm{tot}, i j}=\alpha_{a, i j}\left(T_{i}-T_{s, j}\right)+\frac{\alpha_{a, i j} \cdot h_{f g, i}}{L e_{i}^{2 / 3} \cdot C_{p, \mathrm{ma}, i}}\left(W_{i}-W_{\mathrm{sat}, s, j}\right)
$$

To relate, in Eq. 4, the saturated air humidity ratio $W_{\text {sat }, s, j}$ to its corresponding surface wall temperature $T_{s, j}$, a proper relationship is required. Many authors, such as Wu and Bong (1994), Liang et al. (2000), and Sharqawy and Zubair (2008), proposed different schemes to simplify the solution. The linear scheme used in the current study, as expressed in Eq. 5, is the one which was suggested by Sharqawy and Zubair (2008).

$W_{\mathrm{sat}, s, j}\left(T_{s, j}\right)=a_{i j}+b_{i j} \cdot T_{s, j}$

, where $b_{i j}=\frac{W_{i}-W_{\mathrm{sat}, s, j}}{T_{d p, i}-T_{s, j}}$, and $a_{i j}=W_{\mathrm{sat}, s, j}-\left(\frac{W_{i}-W_{\mathrm{sat}, s, j}}{T_{d p, i}-T_{s, j}}\right) T_{s, j}$.

After substituting Eq. 5 into Eq. 4, and taking into account the conduction resistance within half thickness of the wall cell, the total heat transfer between any wall cell and air cell in contact can be now written as: 
$\dot{q}_{\mathrm{tot}, i j}=U_{\text {wet }, i j}\left(T_{i j}^{*}-T_{c, j}\right)$

where

$U_{\text {wet }, i j}=1 /\left(\frac{t_{j} / 2}{k_{j}}+\frac{1}{\alpha_{\text {wet }, i j}}\right)$

$\alpha_{\text {wet }, i j}=\alpha_{a, i j}\left(1+\beta_{i} \cdot b_{i j}\right)$

$\beta_{i}=h_{f g, i} / L e_{i}^{2 / 3} \cdot C_{p, \mathrm{ma}, i}$

$T_{i j}^{*}=\frac{T_{i}+\beta_{i}\left(W_{i}-a_{i j}\right)}{1+\beta_{i} \cdot b_{i j}}$ is the overall heat transfer coefficient for the wet case which accounts for total convection and conduction resistances;

is the total heat transfer coefficient for the wet case, which accounts for sensible and latent heat transfer;

is a parameter resulted from using the Chilton-Colburn analogy; and

is the modified temperature for moist air, if there is no dehumidification then $T_{i j}{ }^{*}=T_{i}$.

For solving the previous system of equations, a set of boundary conditions is needed. Inlet conditions and velocity distributions are known for air. The wall edges are considered to be adiabatic with the surrounding. Only two tubes of the whole evaporator are going to be modeled in this work, so an additional boundary condition is necessary. As a result, both tubes are assumed to have a symmetry condition, adiabatic-section at half the channel height. This condition implies that the heat transferred from a tube to each of the neighboring tubes is the same.

\subsection{Numerical Scheme}

The FVM (Patankar, 1980) is applied along with the semi-explicit method for wall temperature linked equations (SEWTLE) (Corberán et al., 2001) in order to discretize the governing equations presented in the previous subsection. However, it is necessary to assume temperature and humidity ratio profiles for the air to obtain the estimation of the integral of the heat and mass transfer between the moist air and corresponding piece of wall (Eq. 3) in the flow direction. This integration must be consistent with the integration of the coincident terms in Eqs. 1 and 2. The linear fluid temperature variation scheme (LFTV) has been employed, as Corberán et al. (2001) suggested for this application. After discretizing the Laplacian term in Eq. 3 using classical finite difference approach, besides applying the LFTV scheme, Eq. 3 can be now expressed as follows. 


$$
\lambda_{j} \cdot T_{c, j}-\lambda_{j-f} \cdot T_{c, f}-\sum_{k=W, E, S, N} \lambda_{j-k} \cdot T_{c, k}=\sum_{i=1}^{n_{j}} \dot{q}_{\mathrm{tot}, i j} \cdot P_{i j} \cdot \Delta s_{i j}
$$

where

$\lambda_{j-W}=\frac{k_{j-W} \cdot A_{j-W}}{\delta l_{j-W}}, \quad \lambda_{j-E}=\frac{k_{j-E} \cdot A_{j-E}}{\delta l_{j-E}}, \quad \lambda_{j-S}=\frac{k_{j-S} \cdot A_{j-S}}{\delta l_{j-S}}, \quad \lambda_{j-N}=\frac{k_{j-N} \cdot A_{j-N}}{\delta l_{j-N}}$,

$\lambda_{j-f}=\frac{k_{j-f} \cdot A_{j-f}}{\delta l_{j-f}}$, and $\lambda_{j}=\sum_{k=W, E, S, N} \lambda_{j-k}$.

All $\lambda_{j-k}$ terms refer to the thermal conductance between the current wall cell $j$ and the neighboring wall cell in the direction $k$. The direction references are different in the tube and fin cells, the schematic used in the current model is shown in Fig. 3. The term $\lambda_{j-f}$ is only evaluated if the current cell $j$ is a tube cell, to account for the heat conduction from/to the adjacent fin cell.

While the discretization of air-side total heat transfer equation (Eq. 6) is represented by

$$
\dot{q}_{\mathrm{tot}, i j}=U_{\mathrm{wet}, i j}\left(\bar{T}_{i j}^{*}-T_{c, j}\right)
$$

, where $\bar{T}_{i j}^{*}=\frac{\left.T_{i j}^{*}\right|^{\text {in }}+\left.T_{i j}^{*}\right|^{\text {out }}}{2}$.

In the same way, The LFTV scheme is also applied to Eqs. 1 and 2 to calculate the outgoing air humidity ratio and temperature, as expressed next in Eqs. 9 and 10, respectively.

$$
\begin{aligned}
& W_{i}^{\text {out }}=\frac{\left\lfloor 1-\left(\sum_{j=1}^{n_{i}} \frac{\alpha_{D, i j} \cdot P_{i j}}{\dot{m}_{i}} \cdot \Delta s_{i} / 2\right)\right\rceil \cdot W_{i}{ }^{\text {in }}+W_{\text {sat }, s, j} \cdot \sum_{j=1}^{n_{i}} \frac{\alpha_{D, i j} \cdot P_{i j}}{m_{i}} \cdot \Delta s_{i}}{\left.\left\lfloor 1+\left(\sum_{j=1}^{n_{i}} \frac{\alpha_{D, i j} \cdot P_{i j}}{\dot{m}_{i}} \cdot \Delta s_{i} / 2\right)\right\rceil\right]} \\
& T_{i}^{\text {out }}=\frac{\left\lfloor 1-\left(\sum_{j=1}^{n_{i}} \frac{\alpha_{a, i j} \cdot P_{i j}}{\dot{m}_{i} \cdot \bar{C}_{p, \mathrm{~m} \mathrm{a}, i}} \cdot \Delta s_{i} / 2\right)\right\rfloor \cdot T_{i}^{\mathrm{in}}+T_{s, j} \cdot \sum_{j=1}^{n_{i}} \frac{\alpha_{a, i j} \cdot P_{i j}}{\dot{m}_{i} \cdot \bar{C}_{p, \mathrm{~m} \mathrm{a}, i}} \cdot \Delta s_{i}}{\left\lceil\mid\left(\sum_{i} \frac{\alpha_{a, i j} \cdot P_{i j}}{\dot{m}_{i} \cdot \bar{C}} \cdot \Delta s_{p, \mathrm{ma}, i} / 2\right)\right\rceil}
\end{aligned}
$$




\section{NUMERICAL COMPARISON OF THE FIN2D-W AND CLASSICAL $\varepsilon$-NTU MODELS FOR DIFFERENT DEHUMIDIFYING CONDITIONS AND SUPERHEAT VALUES}

The classical $\varepsilon-\mathrm{NTU}$ approach is considered to be one of the most favorite methods for modeling heat exchangers in the literature, because of its simplicity and calculation speed. However, it adopts many implicit assumptions to simplify the solution, as explained before, during its development. Accordingly, the authors have decided to compare the Fin2D-W air-side heat transfer results with the general $\varepsilon$-NTU approach; as outlined in Kays and London (1984) for dry cases, and Ragazzi (1995) for wet cases. This allows for assessing the performance of the proposed model for different dehumidifying conditions and superheat values, additionally, identifying the errors resulted from the widely used modeling assumptions.

The verification process of the Fin2D-W model was already carried out by Hassan et al. (2015). Moreover, the case studied by Hassan et al. (2015) is also used in the current work. The case study consists of two evaporator tubes with a tube length of $8.6 \mathrm{~cm}$, fin height of $8 \mathrm{~mm}$, fin thickness of $0.152 \mathrm{~mm}$, fin pitch of $1.59 \mathrm{~mm}$, and only one refrigerant pass. These geometrical specifications are sufficient to identify the sources of deviations between the Fin2D-W and $\varepsilon$-NTU models in this kind of heat exchangers; since the relevant dimension to be discretized, in order to face the main prediction challenges which were discussed, is the fin height. To obtain a detailed representation of the fin and air flow in both longitudinal and transverse directions, The evaporator piece in the case study is discretized into a grid of $\{3,1,10,30,10\}$.

In the classical $\varepsilon$-NTU modeling, the fins are assumed to be adiabatic at half the height which results in two segments (upper and lower). Each segment is treated separately using the corresponding adiabatic-fin-tip efficiency (for wet or dry condition) and thermal effectiveness relationship. To identify whether the segment is totally wet or dry, the following condition (Eq. 11), which was proposed by Jiang et al. (2006), is adopted in the current $\varepsilon$-NTU model:

$\bar{T}_{f, \mathrm{dry}}=\eta_{f, \mathrm{dry}}\left(T_{f B}-\bar{T}_{a}\right)+\bar{T}_{a}$

where $\bar{T}_{f, \text { ary }}$ is the average fin temperature evaluated under dry condition assumption by using the fin theory. If $\bar{T}_{f, \text { dry }}<\bar{T}_{d p}$, then the segment will be assumed to be totally wet; otherwise, it will be assumed to be totally dry. 
To allow for proper comparison between the two models the following assumptions are made: firstly, the tubes temperatures are assumed to be given; secondly, the air-side heat transfer coefficient is constant; finally, the properties of moist air are constant. Accordingly, the thermal effectiveness relationship used is $\varepsilon=1$-exp (-NTU) (Bergman et al., 2011, ch. 11, pp. 723-730).

Three cases have been chosen to represent different inlet air conditions to the evaporator, as seen in Table 1 . These cases cover a wide range of refrigeration and air conditioning applications.

A range of lower and upper tubes temperatures has been selected to capture different dehumidifying conditions and simulate the presence of refrigerant superheat in the evaporator tubes. The superheat ( $\mathrm{SH})$, in the current study, is assumed as the difference between upper tube temperature $T_{u t}$ and lower tube temperature $T_{l t}$. This scenario corresponds to a case in which the refrigerant evaporates in the bottom tube while is superheated in the upper one. The air-side sensible heat transfer coefficient was assumed to be $48 \mathrm{~W} \mathrm{~m}^{-2} \mathrm{~K}^{-1}$, which is considered to be an average normal value in air-to-refrigerant heat exchangers (Bergman et al., 2011). Since the air velocity does not change, the heat transfer coefficient remained the same for all the cases under study. For moist air, the Lewis number is close to unity (Coney et al., 1989b), so a Lewis number of unity was assumed in the current study. The comparison results between the two models are discussed next.

Figs. 4-6 (part a) show the relative deviations in sensible heat transfer between the two models. The average values of these deviations for Cases I, II, and III are 4.1\%, 3.3\%, and 2.0\%, respectively. The main source of these differences is the assumption of uniform air temperature between tubes, which is adopted by the $\varepsilon$-NTU model. It is worth mentioning that Martínez-Ballester et al. (2011) reported similar deviations for the sensible heat transfer results in a comparative study between the $\varepsilon$-NTU approach and a $2 \mathrm{D}$ numerical model for minichannel $\mathrm{CO}_{2}$ gas cooler.

The main disadvantage of the $\varepsilon$-NTU model that it does not account for partial dehumidification scenarios, so with the increase in superheat, it tends to convert the fin condition suddenly from totally wet to a half wet fin. This, in turn, affects the average fin temperature, because of the change in the released amount of latent heat of water condensation, and subsequently the amount of sensible heat transfer. This could explain the sudden increase in relative deviations in sensible heat transfer between the two models in the transition region, as seen in Figs. 4a, 5a, and 6a. 
The relative deviations in latent heat transfer between the $\varepsilon$-NTU and Fin2D-W models, based on the Fin2D-W model results, for the three inlet air cases under study are illustrated in Figs. 4-6 (part b). In the first region (R1) both models assume a totally wet fin, however, it can be seen in these figures that the $\varepsilon$-NTU model generally overpredicts the amount of latent heat transfer rate compared with the Fin2D-W model. The assumption of uniform humidity ratio along the fin height could be the main responsible for these differences in results.

With a further increase in superheat, the second region (R2) starts. Despite the average fin temperature (Eq. 11) is used by the $\varepsilon$-NTU model for estimating the fin condition, once the fin root temperature becomes very close or equal to the dew point of surrounding air the $\varepsilon$-NTU model immediately converts the status of upper half of the fin from totally wet to totally dry. This is the consequence of high fin efficiency which usually exists in minichannel heat exchangers. On the other hand, the Fin2D-W model still treats the whole fin as totally wet within this region. Usually, R2 is small, and this discrepancy in the fin condition does not affect the results so much. However, for some studied conditions, the $\varepsilon$-NTU model underestimates the amount of latent heat transfer compared with the Fin2D-W model, as seen in Figs. 4b, 5b, and 6b.

To understand more the deviations between the two models in this region; the fin temperature profile and mass flux of condensed water, at half the fin depth along the air flow direction (z-direction), for a point in R2 are shown in Fig. 7. This point represents Case II, when $\mathrm{T}_{\mathrm{lt}}=2.0{ }^{\circ} \mathrm{C}$ and $\mathrm{SH}=15.15 \mathrm{~K}$. It can be clearly noticed that the $\varepsilon$-NTU model fails to predict the actual fin temperature profile, which subsequently results to a misprediction of the real fin dehumidifying condition and amount of latent heat transfer, compared with the Fin2D-W model.

In the third region (R3), unlike the $\varepsilon-\mathrm{NTU}$ model which always assumes that the upper half of the fin is totally dry while the lower half is totally wet, the Fin2D-W model considers any dehumidifying condition for the fin, from $0 \%$ to $100 \%$ wet. It can be noticed from Figs. $4-6$ (part b) that the deviations in latent heat transfer exponentially increase with the increase in superheat, especially with the increase in lower tube temperature. The values of these deviations are up to $33 \%, 144 \%$, and $191 \%$ for Cases I, II, and III, respectively.

The assumption of adiabatic-fin-tip at half the height, which is usually adopted by the classical $\varepsilon$-NTU approach, results in a non-continuous fin temperature profile; while the Fin2D-W model considers a continuous temperature profile. This discrepancy leads to considerable differences as the superheat increases. The fin temperature profile resulted from the $\varepsilon$-NTU model is also affected by the high fin efficiency, which subsequently results in an average 
fin temperature that is too close to the tube wall temperature. This fact, besides the assumption of non-mixed air in the $y$-direction and the misprediction of actual fin condition can lead to these substantial deviations between the two models, which depend on superheat value and tube wall temperature.

To clarify more the impact of adiabatic-fin-tip assumption at half the height on the heat transfer results, Fig. 8 depicts the fin temperature profile and the amount of condensed water at half the fin depth, for a point in R3. This figure represents an extreme condition for Case II, where $\mathrm{T}_{\mathrm{lt}}=12.0^{\circ} \mathrm{C}$ and $\mathrm{SH}=15.0 \mathrm{~K}$. It can be seen that the Fin2DW model predicts that approximately $35 \%$ of the fin surface is wet while the rest is dry. However, the $\varepsilon$-NTU model assumes that the upper portion (50\% of the fin height) does not exchange either heat or mass with the surrounding air because the temperature of the whole upper portion is equal to the inlet air temperature. Whereas, the entire lower portion is assumed to be totally wet with an average fin temperature $\approx 12.37{ }^{\circ} \mathrm{C}$, which is very close to the lower tube temperature.

The average relative deviation (ARD) values in latent and total heat transfer rates for each inlet air case are shown in Table 2.

Generally, the ARD values in total heat transfer increase with the increase in inlet air temperature for R1, R2, and R3. However, it can be noticed in Table 2 that the deviations in total heat transfer rate in R3 (partially wet fin region) are more significant than the deviations in other regions. They are substantially affected by the high deviations in latent heat transfer between the two models.

\section{CONCLUSIONS}

The air-side heat and mass transfer results of a 2D numerical model for minichannel evaporators (Fin2D-W), which accounts for partial dehumidification scenarios and heat conduction through the fins, were compared with the classical $\varepsilon-\mathrm{NTU}$ approach.

The results revealed that $\varepsilon$-NTU model is not able to capture the precise dehumidifying condition of the fin, compared with the Fin2D-W model. It only considers three fin conditions 0\%, 50\%, and 100\% wet fin. This is because of the discontinuity in the fin temperature profile, which is a consequence of adapting the adiabatic-fin-tip assumption. In addition to this assumption, the high fin efficiency which usually exists in minichannel heat exchangers makes the heat transfer results very sensitive to the tube temperature. This situation becomes more important in the presence of temperature difference between the evaporator tubes. 
In the region of totally wet fin, the relative deviations in total heat transfer are up to $4.33 \%$. The main source of the deviations between the two approaches could be the $\varepsilon$-NTU modeling assumption of uniform air temperature and humidity ratio along the fin height.

However in the region of partially wet fin, the deviations between the two approaches start to increase significantly with the increase in superheat value, especially the deviations in latent heat transfer. This is the consequence of using adiabatic-fin-tip assumption at half the height, which results in large differences in the fin temperature profile and dehumidifying condition between the two models. The relative deviations in total heat transfer between the two approaches for Cases I, II, and III are up to $16 \%, 30 \%$, and 52\%, respectively.

\section{ACKNOWLEDGEMENT}

Abdelrahman H. Hassan is partially supported by Santiago Grisolía 2012 program which is funded by the Valencian Community under reference number: GRISOLIA/2012/005. Financial support from the Spanish Ministry of Economy and Finance, project number: DPI2011-26771-C02-01, is also gratefully acknowledged.

\section{REFERENCES}

Asinari, P., Cecchinato, L., Fornasieri, E. 2004. Effects of thermal conduction in microchannel gas coolers for carbon dioxide. International Journal of Refrigeration 27, 577-586.

Bergman, T.L., Lavine, A.S., Incropera, F.P., DeWitt, D.P. 2011. Fundamentals of Heat and Mass Transfer. 7th edition. John Wiley and Sons, New Jersey.

Coney, J.E.R., Kazeminejad, H., Sheppard, C. 1989a. Dehumidification of air on a vertical rectangular fin: a numerical study. Journal of Mechanical Engineering Science 203, 165-175.

Coney, J.E.R., Sheppard, C.G. W., El-Shafei, E.A.M. 1989b. Fin performance with condensation from humid air: A numerical investigation. International Journal of Heat and Fluid Flow 10, 224-231.

Corberán, J.M., De-Cordoba, P.F., Gonzálvez-Macia, J., Alias, F. 2001. Semiexplicit method for wall temperature linked equations (SEWTLE): A general finite-volume technique for the calculation of complex heat exchangers. Numerical Heat Transfer, Part B: Fundamentals 40(1), 37-59. 
Corberán, J.M., Gonzálvez, J., Montes, P., Blasco, R. 2002. “ART” a computer code to assist the design of refrigeration and $\mathrm{A} / \mathrm{C}$ equipment. In: International Refrigeration and Air Conditioning Conference at Purdue, IN, USA.

Domanski, P.A. 2003. EVAP-COND, simulation models for finned tube heat exchangers. National Institute of Standards and Technology Building and Fire Research Laboratory, Gaithersburg, MD, USA.

Gossard, J.J., Han, X., Ramalingam, M., Sommers, A.D. 2013. Investigating the thermal-hydraulic performance of new refrigerant mixtures through numerical simulation of minichannel and microchannel evaporators. Applied Thermal Engineering 50(1), 1291-1298.

Hassan, A.H., Martinez-Ballester, S., Gonzálvez-Maciá, J. 2015. A comparative study between a two-dimensional numerical minichannel evaporator model and a classical effectiveness-NTU approach under different dehumidifying conditions. Science and Technology for the Built Environment 21(5), 681-692.

Huang, L., Bacellar, D., Aute, V., Radermacher, R., 2015. Variable geometry microchannel heat exchanger modeling under dry, wet and partially wet surface conditions accounting for tube-to-tube heat conduction. Science and Technology for the Built Environment 21(5), 703-717.

IMST-ART. 2010. Simulation tool to assist the selection, design and optimization of refrigeration equipment and components. Universitat Politècnica de València, Instituto de Ingeniería Energética, Spain. [Online] Available at: http://www.imst-art.com.

Jiang, H., Aute, V., Radermacher, R. 2006. Coil designer: A general-purpose simulation and design tool for air-torefrigerant heat exchangers. International Journal of Refrigeration 29, 601-610.

Kays, W.M., London, A.L. 1984. Compact Heat Exchangers. 3rd Ed. New York: McGraw-Hill.

Kuehn, T.H., Ramsey, J.W., Threlkeld, J.L. 1998. Thermal Environmental Engineering. 3rd ed. Upper Saddle River, NJ: Prentice-Hall, Inc.

Liang, S.Y., Wong, T.N., Nathan G.K. 2000. Comparison of one-dimensional and two-dimensional models for wet surface fin efficiency of a plate-fin-tube heat exchanger. Applied Thermal Engineering 20, 941-962.

Liang, S.Y., Wong, T.N., Nathan, G.K. 2001. Numerical and experimental studies of refrigerant circuitry of evaporator coils. International Journal of Refrigeration 24, 823-833. 
Martínez-Ballester, S., Corberán, J.M., Gonzálvez-Maciá, J., Domanski, P.A. 2011. Impact of classical assumptions in modelling a microchannel gas cooler. International Journal of Refrigeration 34(8), 1898-1910.

Patankar, S.V. 1980. Numerical Heat Transfer and Fluid Flow. Hemisphere, New York.

Ragazzi, F. 1995. Thermodynamic Optimization of Evaporators with Zeotropic Refrigerant Mixtures. Ph.D. Dissertation, University of Illinois, Urbana-Champaign.

Ren, T., Ding, G., Wang, T., Hu, H. 2013. A general three-dimensional simulation approach for micro-channel heat exchanger based on graph theory. Applied Thermal Engineering 59, 660-674.

Sharqawy, M.H., Zubair, S.M. 2008. Efficiency and optimization of straight fins with combined heat and mass transfer - An analytical solution. Applied Thermal Engineering 28, 2279-2288.

Singh, V., Aute, V., Radermacher, R. 2008. Numerical approach for modeling air-to-refrigerant fin-and-tube heat exchanger with tube-to-tube heat transfer. International Journal of Refrigeration 31(8), 1414-1425.

Threlkeld, J. L. 1970. Thermal Environmental Engineering. Second edition. Prentice-Hall Inc., New Jersey.

Wu, G., Bong, T.-Y. 1994. Overall efficiency of a straight fin with combined heat and mass transfer. ASHRAE Transaction 100, 367-374.

Wu, X.M., Webb, R.L. 2002. Thermal and hydraulic analysis of a brazed aluminum evaporator. Applied Thermal Engineering 22, 1369-1390.

Yin, X.W., Wang, W., Patnaik, V., Zhou, J.S., Huang, X.C. 2015. Evaluation of microchannel condenser characteristics by numerical simulation. International Journal of Refrigeration 54, 126-141.

Zhao, Y., Liang, Y., Sun, Y., Chen, J. 2012. Development of a mini-channel evaporator model using R1234yf as working fluid. International Journal of Refrigeration 35, 2166-2178. 
(a)

Evaporator segments: a

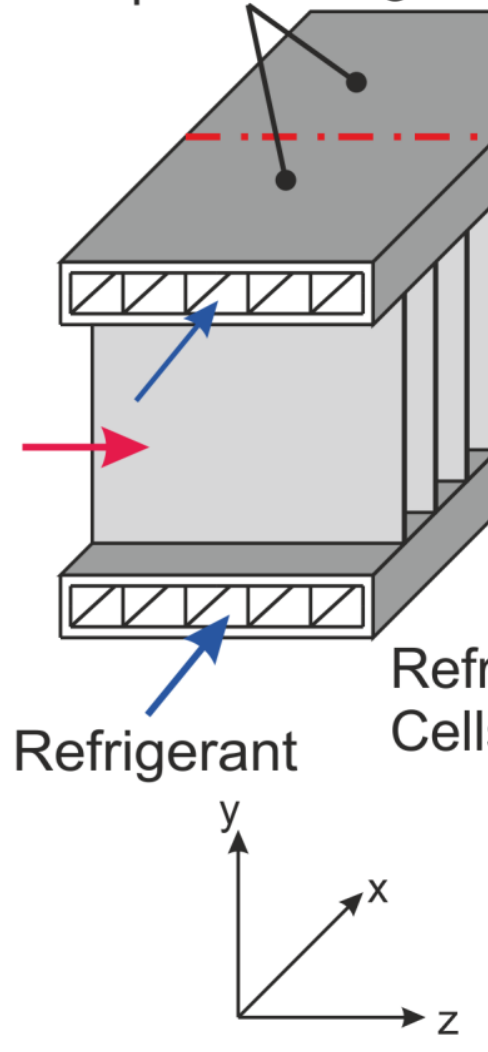

(b)

Moist Air One segment

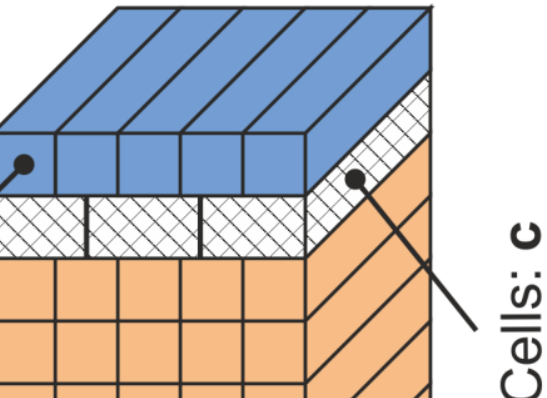

rigerant Cells: $\mathbf{b}$

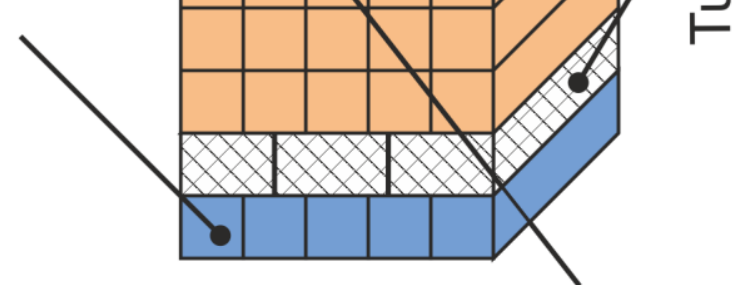

Fin+Air Cells: d,e

Fig. 1 - (a) Main discretization of two tubes in minichannel evaporator. (b) General concept of discretization in one evaporator segment. 


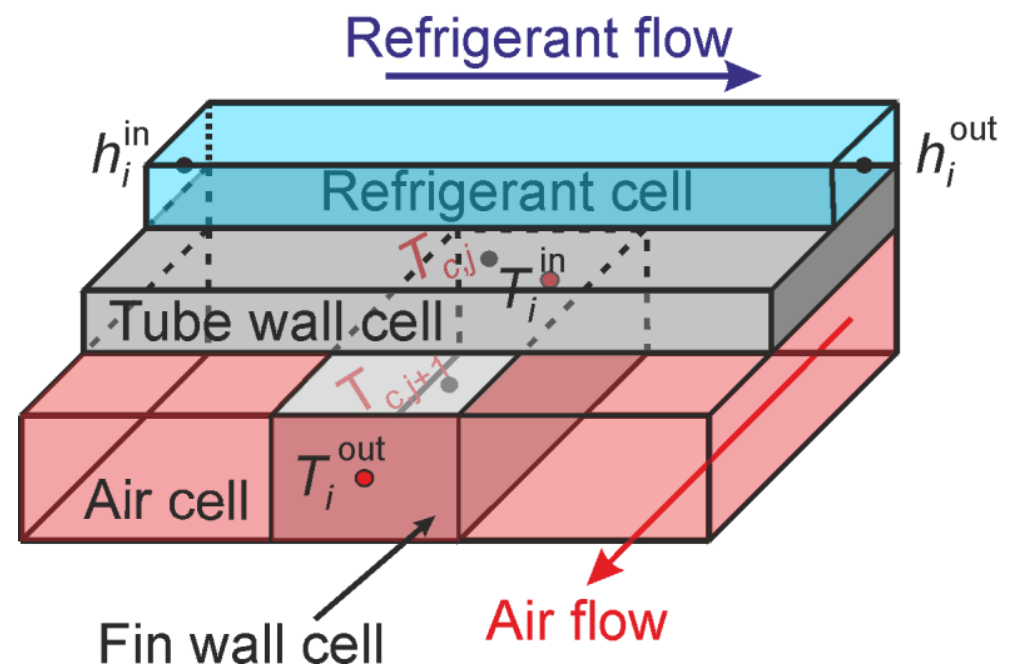

Fig. 2 - Cells schematic and definition of the cell nodes.

a)

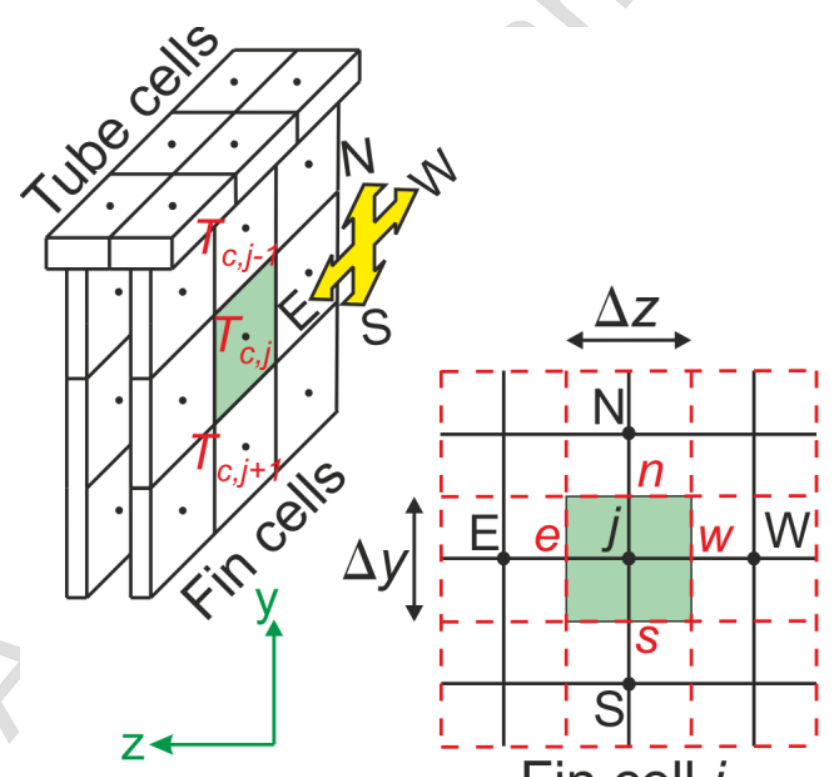

Fin cell $j$

b) 


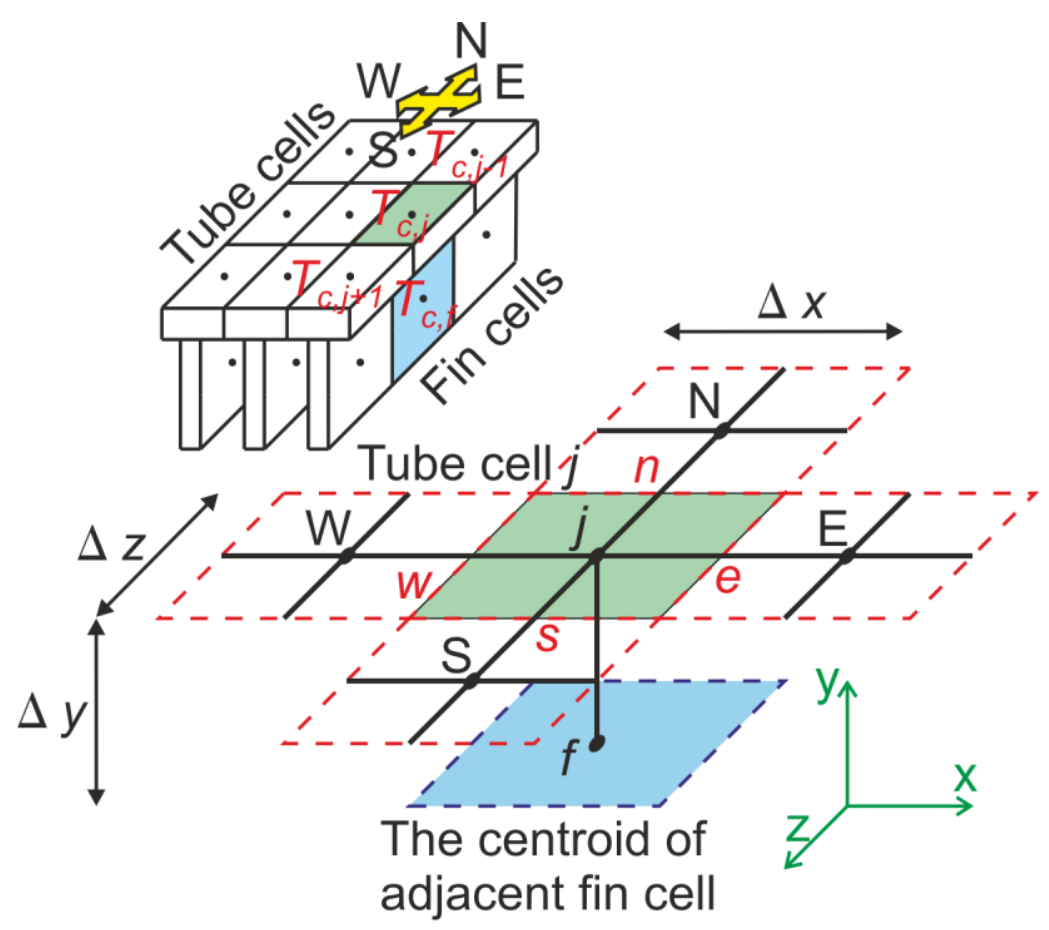

Fig. 3 - Direction references. (a) For fin cells. (b) For tube cells. 

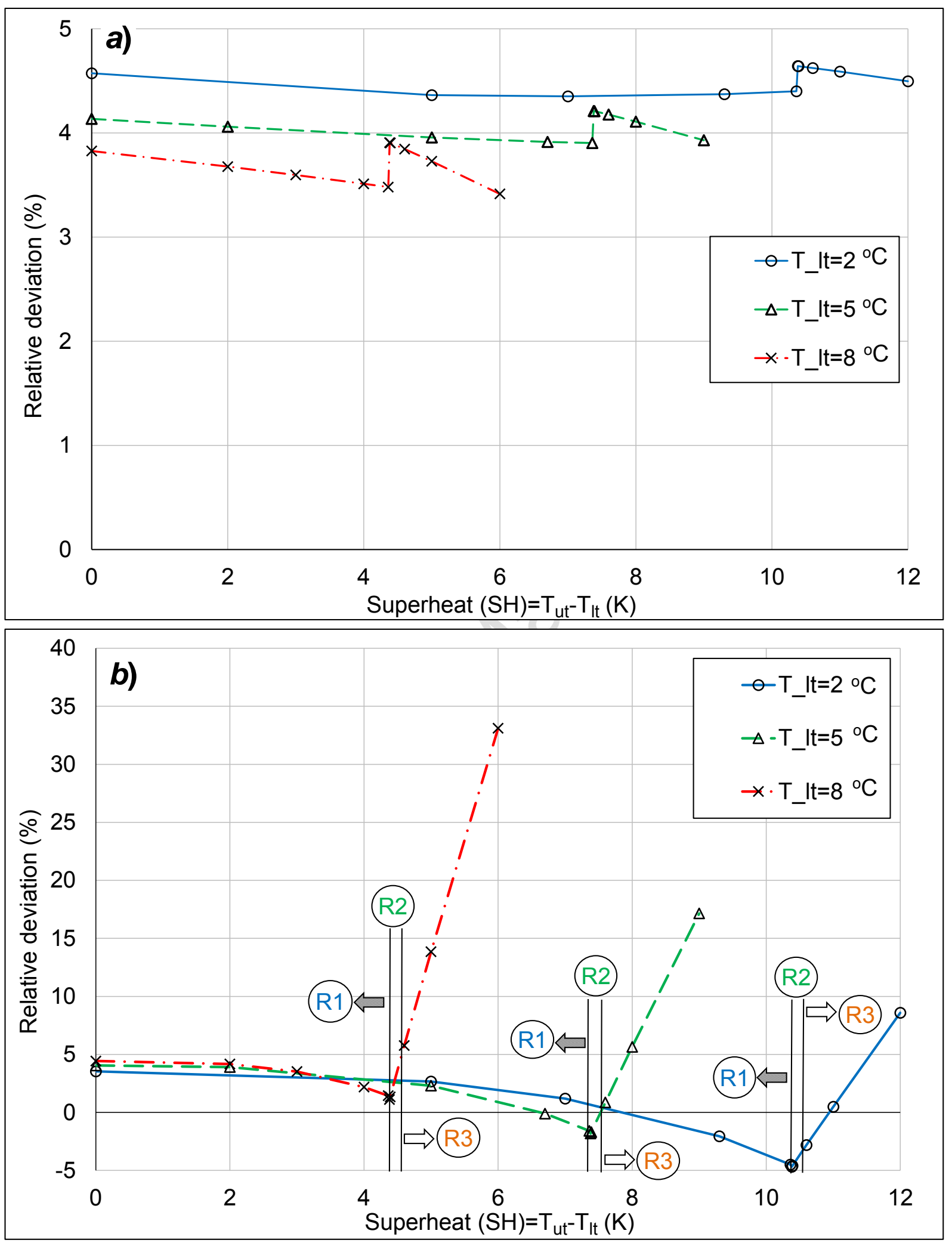

Fig. 4 - Relative deviations in (a) sensible and (b) latent heat transfer between the $\varepsilon$-NTU and Fin2D-W models, for Case I. 

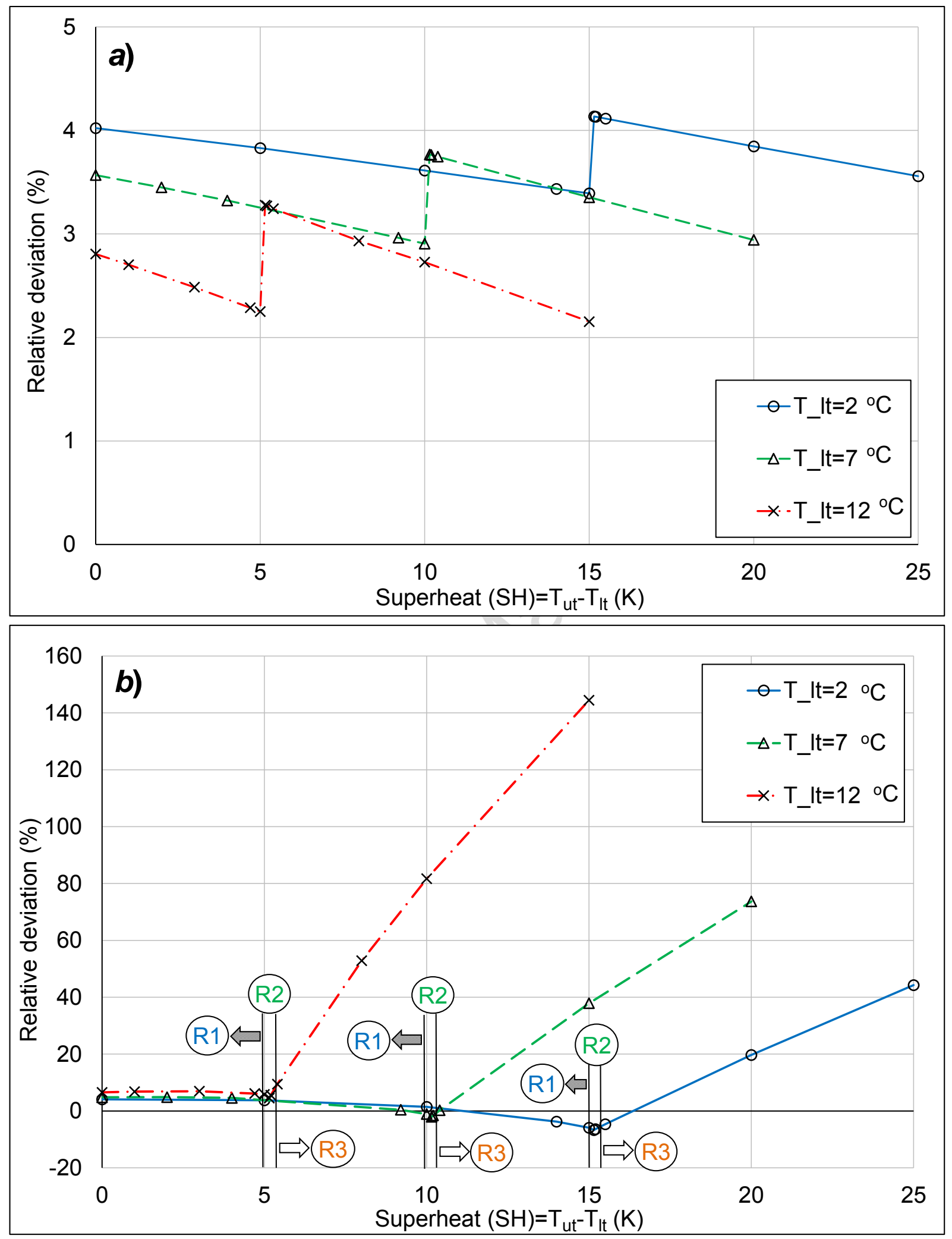

Fig. 5 - Relative deviations in (a) sensible and (b) latent heat transfer between the $8-N T U$ and Fin2D-W models, for Case II. 

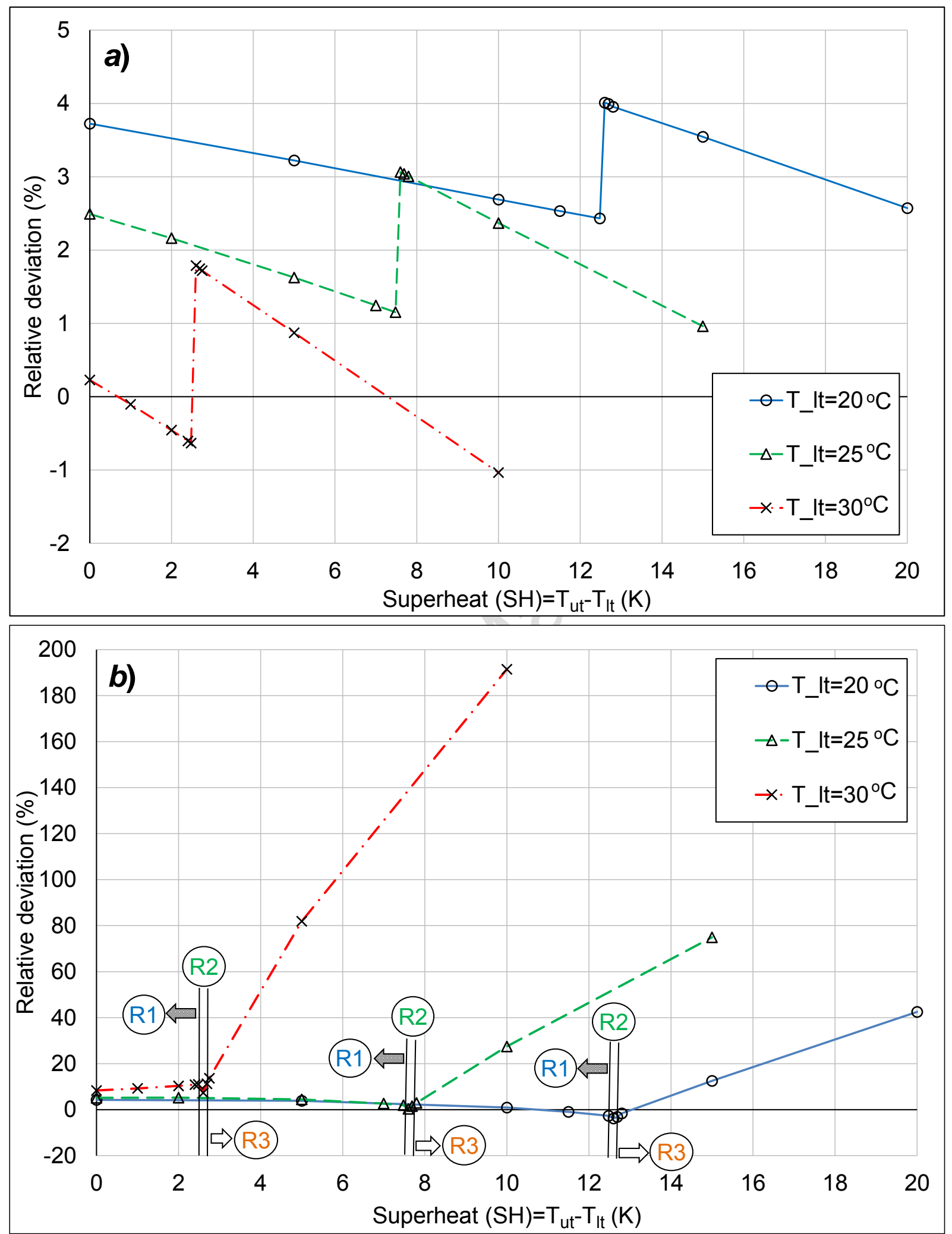

Fig. 6 - Relative deviations in (a) sensible and (b) latent heat transfer between the $\varepsilon$-NTU and Fin2D-W models, for Case III. 

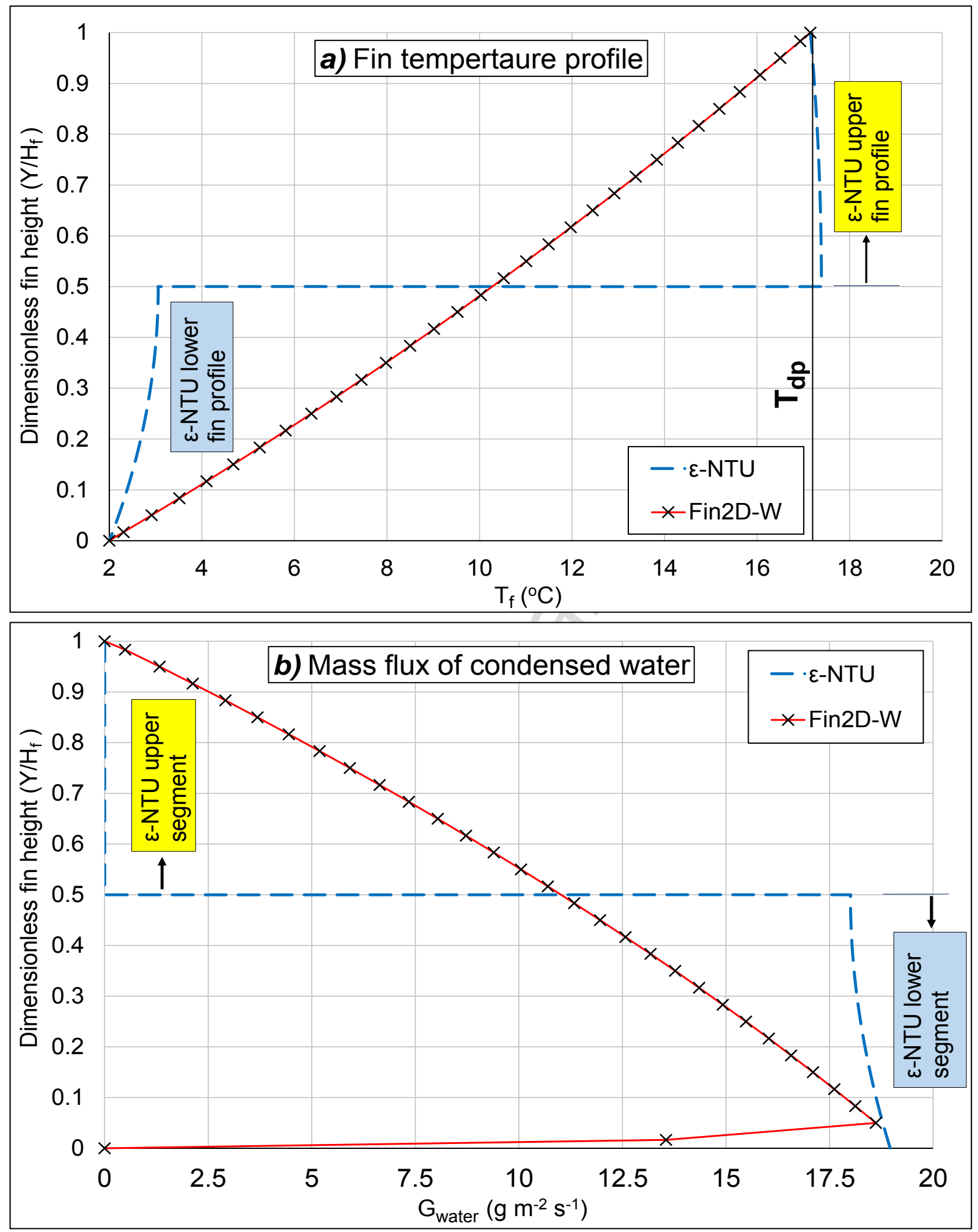

Fig. 7 - (a) Fin temperature profile and (b) mass flux of condensed water, at half the fin depth, for a point in

R2. This represents Case II, when $T_{l t}=2.0^{\circ} \mathrm{C}$ and $\mathrm{SH}=15.15 \mathrm{~K}$. 

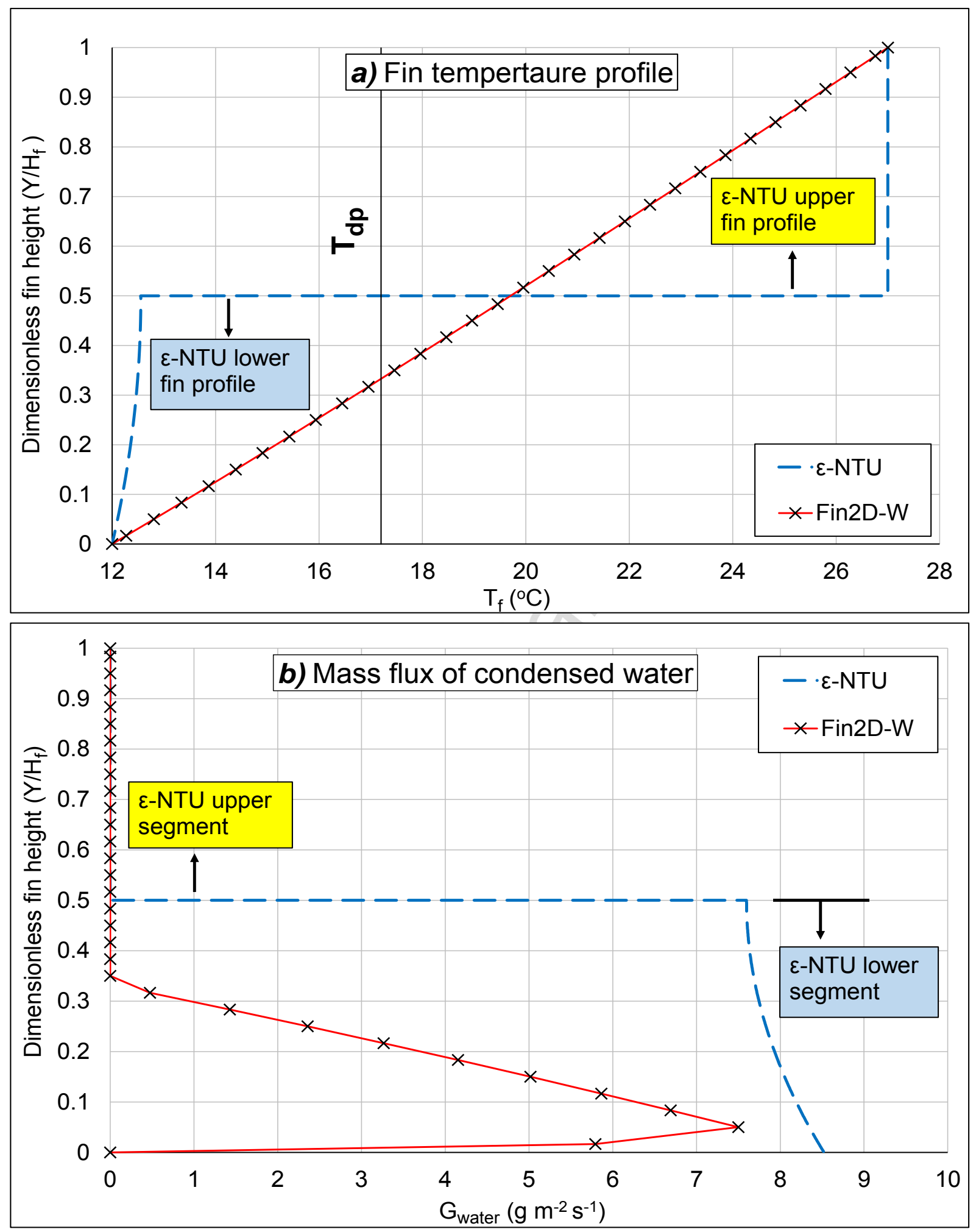

Fig. 8 - (a) Fin temperature profile and (b) mass flux of condensed water, at half the fin depth, for a point in R3. This represents Case II, when $\mathrm{T}_{\mathrm{lt}}=12.0^{\circ} \mathrm{C}$ and $\mathrm{SH}=15.0 \mathrm{~K}$. 
Table 1 - Inlet air conditions to the evaporator under study.

\begin{tabular}{lcccc}
\hline & $T_{a}^{\text {in }}$ & $\mathrm{R} \mathrm{H}_{a}^{\text {in }}$ & $\begin{array}{c}\mathrm{G}_{\mathrm{a}} \\
\left(\mathrm{kg} \mathrm{m}^{-2} \mathrm{~s}^{-1}\right)\end{array}$ & $\begin{array}{c}\text { Inlet pressure } \\
(\mathrm{kPa})\end{array}$ \\
\hline Case I & $\left({ }^{\circ} \mathrm{C}\right)$ & & & \\
Case II & 14 & 90 & 3.34 & 100 \\
Case III & 27 & 55 & & \\
\hline
\end{tabular}

Table 2 - Average relative deviation* (ARD) in latent and total heat transfer between the $\varepsilon$-NTU and Fin2D-W models [\%].

\begin{tabular}{ccccccc}
\hline \multirow{2}{*}{ Case } & \multicolumn{2}{c}{ R1 } & \multicolumn{2}{c}{ R2 } & \multicolumn{2}{c}{ R3 } \\
& ARD in & ARD in & ARD in & ARD in & ARD in & ARD in \\
latent heat & total heat & latent heat & total heat & latent heat & total heat \\
\hline I & 1.7 & 2.91 & -1.72 & 1.48 & 9.2 & 6.3 \\
II & 3.0 & 3.0 & -1.13 & 1.87 & 43.0 & 13.2 \\
III & 5.0 & 3.0 & 2.3 & 2.0 & 50.0 & 19.5 \\
\hline
\end{tabular}

*Relative deviation between the $\varepsilon$-NTU and Fin2D-W models $[\%]=\left[\left(\dot{Q}_{\varepsilon-\mathrm{NTU}}-\dot{Q}_{\mathrm{Fin} 2 \mathrm{D}-\mathrm{w}}\right) / \dot{Q}_{\mathrm{Fin} 2 \mathrm{D}-\mathrm{W}}\right] \times 100$ 